\title{
Saúde Mental e Racismo Contra Negros: Produção Bibliográfica Brasileira dos Últimos Quinze Anos
}

\author{
Marizete Gouveia Damasceno \\ Universidade de Brasília, DF, Brasil.
}

Valeska M. Loyola Zanello

Universidade de Brasília, DF, Brasil.

\begin{abstract}
Resumo: Opressão, agressão e violência são práticas que afetam a saúde mental da pessoa alvo. O racismo, como crença na superioridade de algumas raças sobre outras, que justifica a desigualdade entre os grupos, é uma forma de opressão, de agressão e de violência. O objetivo geral desta revisão sistemática foi encontrar na literatura científica brasileira estudos sobre o impacto do racismo na saúde mental de negros no Brasil; o objetivo específico foi verificar a contribuição da Psicologia nesse tópico. Foram realizadas buscas nas plataformas SciELO e Lilacs, referentes ao período de 1999 a 2014, as quais retornaram 509 artigos, que foram filtrados segundo critérios definidos. Dezenove artigos foram considerados relevantes para análise, mesmo que não tratando exclusivamente do impacto do racismo na saúde mental. Concluiu-se que o tema tem baixa produção acadêmica no Brasil de modo geral, pouca contribuição da Psicologia e menos ainda das demais disciplinas afetas aos CAPS (Centros de Assistência Psicossocial), espaços de assistência pública à saúde mental, buscados majoritariamente pela população negra de baixa renda, dependente dos serviços de saúde pública.
\end{abstract}

Palavras-chave: Racismo, Saúde Mental, População Negra, Negros, Brasil.

\section{Mental Health and Racism against Blacks: Brazilian Publications within the Last Fifteen Years}

\begin{abstract}
Oppression, aggression and violence are practices that affect the mental health of the target person. Racism, the belief that some races are superior to others, which justifies inequalities among groups, is a form of oppression, aggression and violence. The general objective of this systematic review was to find in the Brazilian scientific literature studies on the impact of racism on mental health of the black population in Brazil; the secondary objective was to verify the contributions of psychology to this topic. Searches, carried out in SciELO and Lilacs platforms, returned 509 articles, that were filtered according to criteria of interest. Nineteen articles were considered relevant for analysis, even if they did not deal exclusively with the impact of racism on mental health. It was found that this subject has low academic production in Brazil, low contribution from Psychology and even less, or none, from other disciplines related to the CAPS (Psychosocial Assistance Centers), public agencies for mental health care requested mainly by low income black population dependent on public health services.
\end{abstract}

Keywords: Racism, Mental Health, Black Population, Blacks, Brazil. 


\title{
Salud Mental y Racismo Contra Negros: Producción Bibliográfica Brasileña de los Últimos Quince Años
}

\begin{abstract}
Resumen: La opresión, la agresión y la violencia son prácticas que afectan la salud mental de la persona objetivo. El racismo, como creencia en la superioridad de algunas razas sobre otras, que justifica la desigualdad entre los grupos, es una forma de opresión, de agresión y de violencia. El objetivo general de esta revisión sistemática fue encontrar en la literatura científica brasileña estudios sobre el impacto del racismo en la salud mental de negros en Brasil; el objetivo específico fue verificar la contribución de la psicología en ese tópico. Se realizaron búsquedas en las plataformas SciELO y Lilacs, referentes al período de 1999 a 2014, las cuales retornaron 509 artículos, que fueron filtrados según criterios definidos. Diecinueve de los artículos se consideraron relevantes para el análisis, aunque no tratando exclusivamente del impacto del racismo en la salud mental. Se concluyó que el tema tiene baja producción académica en Brasil de modo general, poca contribución de la psicología y menos aún de las demás disciplinas afines a los CAPS (Centros de Asistencia Psicosocial), espacios de asistencia pública ala salud mental, buscados mayoritariamente por la población negra de baja renta, dependiente de los servicios de salud pública.
\end{abstract}

Palabras clave: Racismo, Salud Mental, Población Negra, Negros, Brasil.

De acordo com a Pesquisa Nacional por Amostra de Domicílios (PNAD) realizada em 2013 pelo Instituto Brasileiro de Geografia e Estatística (IBGE), a população negra é maioria no Brasil, com $53,6 \%$ afirmando ser "preto" ou "pardo" e $45,5 \%$ se declarando de cor branca (IBGE, 2015). A população negra brasileira ocupou historicamente as classes sociais mais pobres e de condições mais precárias na pirâmide social. As condições indignas de vida da população negra persistem, evidenciando o racismo silencioso e não declarado. Permanecem, portanto, o preconceito e discriminação raciais no Brasil (Heringer, 2002; Igreja, 2016; Lins, Lima-Nunes, \& Camino, 2014; Nunes, 2006; Schucman, 2014; Silvério, \& Trinidad, 2012), tal como constataram os estudos promovidos pela Organização das Nações Unidas para a Educação, a Ciência e a Cultura (Unesco), em 1950, no quadro de sua agenda antirracista (Maio, 2001).

Contra esse estado de coisas os movimentos sociais reivindicaram políticas públicas inclusivas, que zelassem pela redução da desigualdade e pela ampliação de acesso aos bens e serviços públicos. Nesse intuito foi formulada a Política Nacional de Saúde Integral da População Negra, que foi aprovada pelo Conse- lho Nacional de Saúde (CNS) em 2006, instituída pelo Ministério da Saúde (MS) em 2009 e foi inserida na dinâmica do Sistema Único de Saúde (SUS). Enfatiza-se aqui o reconhecimento, desde então, pelo Ministério da Saúde, da existência do racismo, das desigualdades étnico-raciais e do racismo institucional no âmbito do SUS (Brasil, 2013; 2016).

Se o quadro é este em termos de saúde geral da população negra, melhor não será quando se afunila para a saúde mental especificamente. Note-se, contudo, que a saúde mental da população negra é contemplada no capítulo terceiro da política acima mencionada, quando se define como "estratégias de gestão": (a) o "fortalecimento da atenção à saúde mental das crianças, adolescentes, jovens, adultos e idosos negros, com vistas à qualificação da atenção para o acompanhamento do crescimento, desenvolvimento e envelhecimento e a prevenção dos agravos decorrentes dos efeitos da discriminação racial e exclusão social" (Brasil, 2013, p. 28), e (b) o "fortalecimento da atenção à saúde mental de mulheres e homens negros, em especial aqueles com transtornos decorrentes do uso de álcool e outras drogas" (Brasil, 2013, p. 28). Ou seja, na Política Nacional de Saúde Integral

${ }^{1}$ O Instituto Brasileiro de Geografia e Estatística (IBGE) considera atualmente cinco categorias para a autodeclararão quanto à característica cor/raça/etnia: 1) branca, 2) preta, 3) amarela (pessoa que se declarou de origem japonesa, chinesa, coreana etc.), 4) parda (pessoa que se declara mulata, cabocla, cafuza, mameluca ou mestiça de preto com pessoa de outra cor/raça/etnia) e 5) indígena (pessoa que se declarou indígena ou índia) (IBGE, 2015). A população negra é considerada como o somatório das pessoas autodeclaradas pretas e pardas. 
da População Negra a saúde mental não ficou esquecida. Além disso, o MS reconheceu que a discriminação racial afeta a saúde mental. Outra estratégia dessa política é o "fomento à realização de estudos e pesquisas sobre o acesso da referida população aos serviços e ações de saúde" (Brasil, 2013, p. 28). Daí conclui-se que a saúde mental negra está incluída entre os temas cuja pesquisa o Estado fomentará.

A discriminação racial e seu impacto em pessoas negras têm sido documentados de forma interdisciplinar. Pieterse, Todd, Neville, \& Carter (2012) apontam o compartilhamento de objetivos entre os trabalhos de Dubois, de Fanon e de Feagin, qual seja, que "as experiências de racismo impõem um fardo psicológico significativo sobre as pessoas" (p. 2). De especial interesse para este estudo é o trabalho de Fanon (1952/2008), que argumentou que o racismo ocidental penetra as estruturas psíquicas do homem moderno de forma que opressor e oprimido terminam regidos por um mesmo registro de recalque e repressão. Contemporaneamente, os próprios estudos de psicólogos multiculturais (Carter, Helms, Parham, Pedersen, Ponterotto, Ridley, os irmãos Sue etc.) são elaborações do pensamento de Frantz Fanon.

O impacto da discriminação racial permanece objeto de estudo e tem ganhado força mundialmente (Carter, 2007; Helms, 1984; Helms, \& Cook, 1999; Paradies, 2006; Ridley, 2005; Sue, \& Sue, 2003, 2016). Os estudos sugerem uma conexão entre racismo e saúde física que parece continuar ao longo da vida da pessoa alvo. Elucidam uma gama de possíveis efeitos, os quais podem resultar do estresse do racismo e, por sua vez, comprometer a saúde mental, culminando no "Dano por Estresse Traumático de Base Racial" ${ }^{2}$ (Race-Based Traumatic Stress Injury - RBTS, segundo Carter, 2007). Os estudos alcançaram o desenvolvimento de uma escala para avaliação desse dano (Carter et al., 2013).

Em um dos raros escritos nacionais (não indexado) sobre o tema, Silva (2005) afirma "sem medo de errar" (p. 129) que a grande maioria da população negra vive em incessante sofrimento mental devido, por um lado, às condições de vida precárias atuais e, por outro, à impossibilidade de antecipar melhor futuro. Ela aponta diversos sintomas físicos e psíquicos advindos da permanente condição "de tensão emocional, de angústia e de ansiedade, com rasgos momentâneos dos distúrbios de conduta e do pensamento" (p.130), vivida cotidianamente pela pessoa alvo do racismo. Essa condição constante causa transtornos tais como taquicardia, hipertensão arterial, úlcera gástrica, ansiedade, ataques de pânico, depressão, dificuldade de se abrir, ataques de raiva violenta e aparentemente não provocada, comprometimento da identidade e distorção do autoconceito. Enfim, a exposição cotidiana a situações humilhantes e constrangedoras pode desencadear um número de processos desorganizadores dos componentes psíquico e emocional (Silva, 2005). Em sendo um problema para a saúde física e mental da pessoa, esse sofrimento causado pelo racismo passa, necessariamente, a ser um problema de saúde pública. Como tal requer proposições de políticas públicas que garantam o direito a um serviço de saúde mental eficaz direcionado especificamente ao sofrimento da população negra produzido pelo racismo.

Historicamente, a vinculação entre raça e doença mental da teoria e da prática alienista do final do século XIX no Brasil levou os psiquiatras a construírem relações entre doença mental e as "raças" que eram consideradas inferiores. Eram "feitas associações entre características étnico-raciais e tipos de caráter, atribuindo-se certas formas de doença mental como típicas de determinadas etnias-raças" (Santos, Schucman e Martins, 2012, p.169). Prevalecia a ideia de que negros e mestiços estavam destinados à loucura, pois eram povos degenerados por definição, argumento que justificou e legitimou a instituição de dispositivos de controle social (Engel, 1999).

Por meio das concepções eugenistas, estava, portanto determinado, preparado e justificado o tratamento a ser dado ao sofrimento psíquico do negro, uma vez que não havia como interferir na etnia das pessoas, na sua destinação à degeneração e à loucura. É válido supor que o pensamento eugenista não considerava que o negro passasse por sofrimento algum: ele apenas seguia seu destino determinado por sua genética. E desta forma, por meio da apropriação de ideias e ideais eugênicos, o sofrimento de minorias raciais e étnicas permaneceu alheio à construção do conhecimento, às ciências humanas, por tempo demasiado longo.

A relação entre raça e saúde, de maneira geral, e mais ainda entre raça e saúde mental especificamente é tema que ficou esquecido no pensamento brasileiro, muito provavelmente como consequência do mito da

${ }^{2}$ Tradução da autora. 
democracia racial brasileira. Na proposta de Zanello e Gouveia (2016), são fortes no Brasil os indícios de que o racismo saiu da visibilidade das teorias raciais do início do século XX e adentrou a invisibilidade da prática clínica atual, em um fenômeno que ultrapassa os limites da psiquiatria e penetra outras áreas clínicas. Um dos indícios é a inexistência da requerida obrigatoriedade de se declarar a cor/raça do paciente quando da coleta inicial de dados cadastrais.

A Psicologia não ficou imune ao alheamento às questões afetas a minorias raciais e étnicas e o lugar que ocupam na sociedade; nesta área a Psicologia tem um histórico de ausência, a exemplo da psiquiatria. Segundo Munanga (2003), vítimas de preconceito racial e discriminação recebem pouca atenção da Psicologia clínica. Ele acredita que a Psicologia brasileira tem muito a produzir no conhecimento do racismo e suas consequências na estrutura psíquica tanto das pessoas-alvo quanto das perpetradoras do racismo.

A saúde mental é um campo pluridisciplinar. A todas disciplinas da saúde mental, inclusive à Psicologia clínica, cabe a prontidão para contribuir com pesquisa e intervenções adequadas a qualquer tipo de população e de dor psíquica. A ajuda psicológica é fundamental também para pessoas que a buscam devido ao sofrimento psíquico pelo qual passam como consequência da experiência de racismo. É crescente o número de psicólogos (as) que acolhem clientes cujo sofrimento psíquico é originado no encontro inter étnico; esses profissionais deparam-se com subjetividades certamente afetadas pelo racismo cotidiano. A ausência de um olhar crítico do profissional impossibilita-lhes atentar para processos de preconceito e discriminação racial presentes no sofrimento psíquico de pessoas negras.

Na realidade da Psicologia clínica brasileira inexiste a preocupação com a experiência de minorias étnicas ou raciais. Martins, Santos e Colosso (2013) encontraram apenas um artigo na área clínica (psicanálise), do total de 42 artigos. A tendência da disciplina é europeizante e arianizante na totalidade de seus modelos. A Psicologia social foi, na década de 1930, pioneira nos estudos de relações raciais (Santos et al., 2012), e é até hoje a área de Psicologia que mais produz nessa temática (Martins et al., 2013). É crescente o interesse da Psicologia brasileira em investigar a opressão, a discriminação e a humilhação social como produtos das desigualdades nas categorias classe e gênero sem, no entanto, legitimar a categoria raça como variável de importância (Santos, \& Schucman, 2015). Tal realidade gera questionamento sobre a produção da Psicologia clínica relativa às minorias raciais e étnicas.

Levando-se em consideração o forte impacto do racismo na saúde mental, como reconhecido pela Organização Mundial de Saúde (OMS, 2001) e pelo MS, e sua aparente invisibilidade como elemento importante na construção do sofrimento psíquico negro, o presente trabalho teve como objetivo geral fazer um levantamento e mapear o que foi publicado sobre o tema no Brasil, de 1999 a 2014. Como objetivo específico, buscou-se verificar a contribuição que a Psicologia Clínica tem dado para esse debate.

\section{Metodologia}

Para fazer o levantamento e mapeamento da produção bibliográfica brasileira sobre o tema saúde mental e racismo, foram escolhidas duas grandes plataformas de periódicos científicos latino-americanos: o SciELO e o Lilacs. A escolha das bases de dados justifica-se por aglutinarem parcela significativa de periódicos brasileiros indexados. Ambas possuem textos completos e de acesso gratuito. SciELO (Scientific Electronic Library Online) é uma biblioteca multidisciplinar, enquanto que a Lilacs (Literatura Latino-Americana e do Caribe em Ciências da Saúde) é um índice, que abrange exclusivamente a produção em ciências da saúde. Em ambas as plataformas a pesquisa foi feita com o recorte geográfico "Brasil".

O período pesquisado foi de 1999 a 2014. A escolha do recorte temporal longo para as publicações justifica-se exatamente pelos indícios de serem essas escassas, quiçá inexistentes. Esta busca foi realizada entre 30 de setembro de 2014 e 30 de novembro de 2014. Os descritores pesquisados foram Psicologia Clínica e Saúde Mental e equivalentes de um lado, e Racismo e correlatos, de outro. A escolha dos descritores de profissões privilegiou as categorias profissionais presentes no Centro de Assistência Psicossocial (CAPS): Psicóloga(o), Psiquiatra, Assistente Social, Terapeuta Ocupacional e Enfermeiro(a). É uma literatura importante por mostrar as pesquisas feitas nesses campos e o possível impacto na e/ou da formação desses profissionais.

O grupo de descritores relativos à Psicologia Clínica e Saúde Mental e equivalentes foi composto por 48 descritores: abordagem human*, abordagem multicultural, aconselhamento psicológico, adoe- 
cimento mental, adoecimento psicológico, adoecimento psíquico, análise comportamental, análise existencial, assistência psicológica, atendimento psicológico, doença mental, doença psicológica, doença psíquica, gestalt terapia, psicologia clínica, saúde mental, saúde psicológica, saúde psíquica, sofrimento mental, sofrimento psicológico, sofrimento psíquico, terapia de base analítica, terapia de base humanística, terapia existencial, terapia multicultural, transtorno mental, transtorno psicológico, transtorno psíquico, transtornos mentais comuns, tratamento psicológico, trauma de base racial, ansiedade, depressão, psicanálise, psicanalista, psicologia, psicólogo, psicopatologia, psicoterapia, psicoterapeuta psiquiatria, psiquiatra, serviço social, assistente social, terap* ocupacional, enfermagem enfermeir*, trauma.

O grupo relativo a racismo e correlatos incluiu termos correspondentes a formas de manifestações de racismo e termos especificamente relativos à população negra, no total de 15 descritores: assédio racial, discriminação racial, injúria racial, ofensa racial, preconceito racial, relações étnico-raciais, relações raciais, violência racial, afrodescendente* ou afro-descendente*, etnia, negr*, negritude, raça, racia*, racismo.

Os descritores do primeiro grupo foram cruzados com os do segundo grupo, resultando em 720 combinações possíveis. A busca nas duas plataformas totalizou 509 resultados, sendo 108 na SciELO e 401 na LILACS. Dos 509 trabalhos, quatro não estavam disponíveis virtual ou fisicamente, foram solicitados via Programa de Comutação Bibliográfica (COMUT) e recebidos com êxito.

Os 509 trabalhos passaram por leitura do resumo e posterior filtragem pelos seguintes critérios de exclusão: (a) itens em duplicidade, ou seja, os artigos repetidos foram considerados apenas uma vez, as duplicadas foram descartadas; (b) trabalhos que, apesar de conterem ambos os descritores, não foram classificados como relevantes para a proposta desta pesquisa, por pertencerem a áreas do conhecimento não afins (por exemplo, HIV e comportamento sexual em Rio Negro); (c) itens que não eram artigo científico publicado em periódico indexado (teses, dissertações, capítulos, resumos, livros, manuais, informes, relatórios etc.); (d) estudos que não tratavam de população brasileira nem de contexto brasileiro. Artigos que versavam sobre a saúde mental em geral, onde se pesquisou apenas um aspecto da saúde da população negra, não foram incluídos. O racismo necessariamente teria que ser foco; já a saúde mental poderia ser foco ou fundo.

Inicialmente o levantamento bibliográfico trazia como critério artigos que apresentassem a situação de intervenção. Uma vez encontrado apenas um artigo que lidava com a situação de intervenção, decidiu-se pela exclusão deste critério. Foram encontrados, assim, dezenove artigos que tratavam da questão do racismo e da saúde mental de pessoas negras, que servem de pavimentação para o entendimento do tema deste trabalho.

A Figura 1 ilustra o processo completo de seleção descrito.

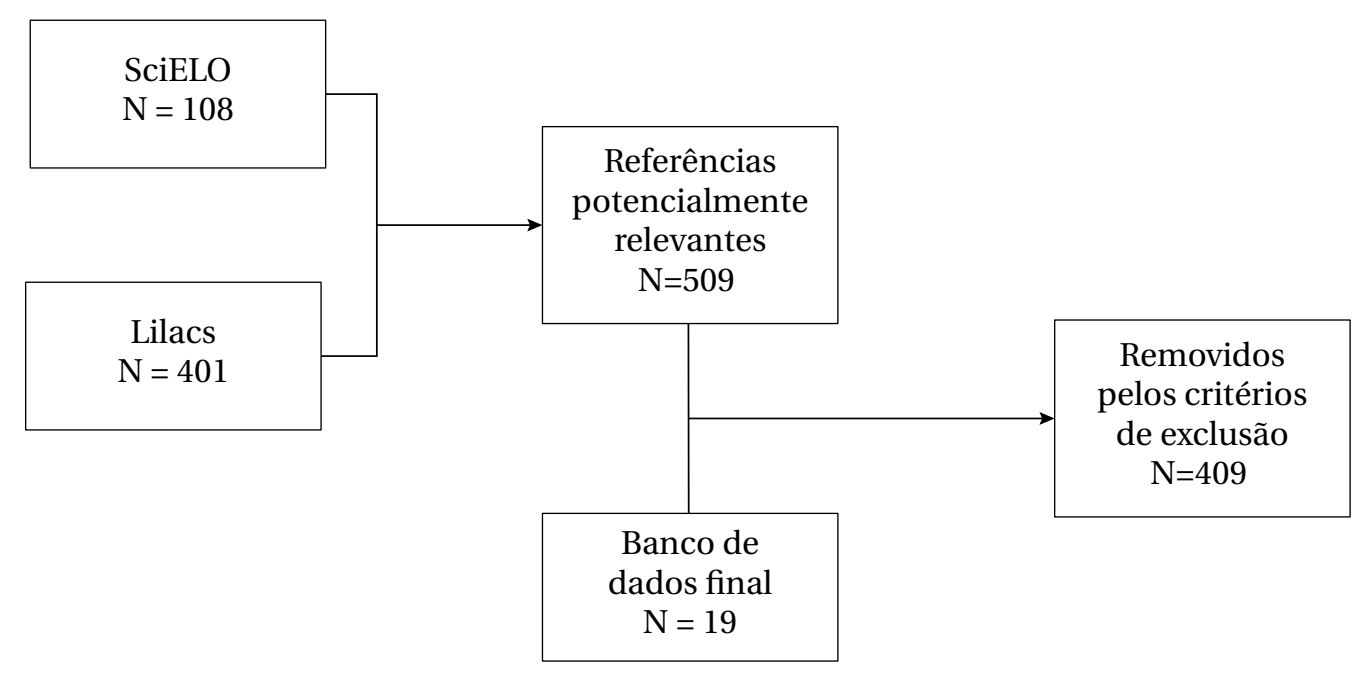

Figura 1

Processo de seleção dos trabalhos encontrados. 


\section{Resultados e discussão}

Os 19 artigos foram lidos em sua totalidade, para produção de novos resumos.

Nos resultados apresenta-se a pífia produção do período estudado (1999-2014). Faz-se mister destacar, no entanto, que apesar dessa exígua produção, a Psicologia tem contribuído de maneira mais efetiva dentre as disciplinas de serviços de saúde. Os temas variaram e distribuíram-se em cinco categorias como mostra a tabela abaixo (Tabela 1), e serão apresentados em seguida, separados segundo a categoria temática, criada a partir do agrupamento de artigos sob um nome genérico, com base nas características compartilhadas de seus conteúdos (Bardin, 2011; Koller, Couto, \& Hohendorff, 2014).

\section{Tema A: Impacto do racismo/discriminação (social e institucional) na saúde mental}

Nesta categoria foram inseridos dois artigos: um de autoria de profissional da Psicologia (Bastos, Barros, Celeste, Paradies, \& Faerstein, 2014), publicado em periódico da área de Saúde Pública e o outro oriundo da Enfermagem (Cruz, 2004), com publicação em periódico da mesma área.

Bastos et al. (2014) realizaram estudo empírico quantitativo, desenvolvido no contexto de um projeto de pesquisa que incluía o desenvolvimento e a avaliação psicométrica de um novo instrumento de autorrelato de experiências pessoais com discriminação (de raça, classe e idade). Os autores objetivaram preencher a lacuna de pesquisa em discriminação ao

Tabela 1

Distribuição numérica dos artigos por categorização temática.

\begin{tabular}{lcrll}
\hline \multicolumn{1}{c}{ Tema } & $\mathrm{N}$ & $\%$ & \multicolumn{1}{c}{ Área 1\%/a Autor/a } & \multicolumn{1}{c}{ Área Periódico } \\
\hline Impacto do racismo/ & 2 & 10,5 & Psicologia: 1 & Saúde Pública: 1 \\
discriminação (social e & & & Psiquiatria: 0 \\
institucional) na saúde mental & & Serviço Social: 0 & Enfermagem:1 \\
& & Terapia Ocupacional: 0 & \\
& & Enfermagem: 1 &
\end{tabular}

Abordagem histórica: incorporação do racismo em teorias psicológicas / psiquiátricas

Percepção de psicólogos da saúde mental sobre o racismo
$9 \quad 47,4 \quad$ Psicologia: 5

Psiquiatria: 2

Serviço Social: 0

Terapia Ocupacional: 0

Enfermagem: 0

Antropologia Social: 1

História: 1

$1 \quad 5,3 \quad$ Psicologia
Saúde

Psicologia: 4

Psicopatologia: 3

Saúde Coletiva: 1

História, Ciências,

Saúde:1
A Psicologia clínica/psiquiatria nas relações raciais ou nas relações que envolvam alteridade

Crítica epistemológica/ metodológica à Psicologia
5 26,3 Psicologia//Intervenção: 1 Psicologia//Análise social: 1 Medicina Social//Análise social: 1 Psicologia//Formação do Psicólogo: 2
Saúde Social: 1

Psicologia: 2

Psicanálise: 1

Etnia e Doenças: 1 
coletar informações fora dos Estados Unidos, avaliar experiências discriminatórias com múltiplas atribuições e explorar interações e associações com transtornos mentais comuns. Participaram 424 estudantes brasileiros de graduação em universidade pública

Ao estudar, porém o impacto de múltiplas discriminações na saúde mental, na crença de "aprofundar o entendimento de discriminação como um fenômeno social, como ele se manifesta e como pode ser combatido" (p. 177), o impacto da discriminação racial perde sua centralidade e dilui-se na interação com outras discriminações. Ao diluirmos o tema, o objetivo foge da esfera racial e, portanto, deixa de fomentar políticas públicas para a população negra, e leva nossa pesquisa em relações raciais e saúde mental a permanecer indefinidamente incipiente. É importante, ainda, mencionar que o estudo considerou cor/raça, classe e idade, e não considerou a dimensão gênero, que poderia levar a resultados diferentes. Por fim, o trabalho como um todo sugere, em uma eventual replicação mais rigor metodológico, principalmente em se tratando de desenvolvimento e validação de instrumento psicométrico.

A revisão bibliográfica realizada por Cruz (2004), de 1990 a 2003, na área de enfermagem, analisou a situação da mulher negra em atendimento pelo SUS, com o objetivo de buscar informações sobre as quais basear a criação de ações afirmativas em face ao racismo e ao sexismo institucionais sofridos pelas mulheres negras no âmbito do SUS. A autora: (a) verificou que o desconhecimento das necessidades da mulher negra por parte das instituições e dos profissionais de saúde contribui para a persistência de estruturas de discriminação; (b) constatou que o número de textos sobre saúde da mulher negra, violência contra mulheres, violência doméstica é exíguo; (c) observou o impacto do racismo, do sexismo e da discriminação sobre a saúde mental da mulher negra a partir da constatação de distúrbio da autoestima e distúrbio do autoconceito; (d) atribuiu a presença do sofrimento psíquico à opressão, materializado na taxa de mortalidade por transtornos mentais, superior ao de pacientes brancas, provavelmente resultantes de tratamento racializado; (e) sugeriu intervenções afirmativas possíveis de serem efetuadas por todos os envolvidos: a paciente negra, os profissionais, as instituições, a sociedade civil organizada e os gestores do SUS.

É considerável o número de prejuízos que atingem a mulher negra, levantados já há mais de uma década, por Cruz (2004). Desde então tem crescido a pesquisa sobre interseccionalidade, conceito que expressa o fato de que formas sexuais de injustiça são análogas e empiricamente entrelaçadas com outras formas de injustiça, como, por exemplo, as relativas a raça, etnia, classe e religião (Kerner, 2012). Apesar de não ser este o tema deste trabalho, é válido apontar que a desconstrução da imagem negativa das mulheres negras, duplamente invisibilizadas, é parte fundamental do processo de desconstrução do racismo como um todo, sendo atualmente a interseccionalidade gênero-raça um crescente e promissor campo de pesquisa nesse sentido.

\section{Tema B: Abordagem histórica: incorporação do racismo em teorias psicológicas/psiquiátricas}

Este tema foi contemplado com nove artigos. São várias as áreas profissionais do primeiro autor/ da primeira autora: cinco da Psicologia (Masiero, 2002; 2005; Santos et al., 2012; Serra, \& Scarcelli, 2014; Weyler, 2006), dois da Psiquiatria (Oda, 2004; Oda, \& Dalgalarrondo, 2004); um da Antropologia Social (Venancio, 2004) e um da História (Engel, 1999). Seis artigos são referentes à Psiquiatria e três à Psicologia. Já com relação à área do periódico, quatro são de Psicologia (Masiero, 2002; 2005; Santos et al., 2012; Weyler, 2006), três de Psicopatologia (Oda, 2004; Oda, \& Dalgalarrondo, 2004; Serra, \& Scarcelli, 2014); um de Saúde Coletiva (Venancio, 2004) e um da área de História, Ciência e Saúde (Engel, 1999).

Dos nove artigos, oito giram em torno da entrada das teorias raciais, da eugenia e do racismo científico nas teorias psicológicas e psiquiátricas no Brasil. Por exemplo, Masiero (2002) analisou a tentativa de vigilância e disciplinamento das manifestações religiosas de matriz africana, com base em uma Psicologia tomada por ideias eugênicas. Também Masiero (2005) demonstrou como as teorias raciais entraram no âmbito das ciências psicológicas e direcionaram seus conceitos e práticas. Para Weyler (2006), as teorias raciais europeias adotadas a partir de 1870 para entender a loucura cumpriam funções sociais e políticas e influenciaram, com o Estado, na percepção da saúde mental e nas práticas psicológicas e psiquiátricas no Brasil. Serra e Scarcelli (2014) também analisaram a influência da ciência eugênica no trabalho psiquiátrico prático e teórico. Em 1999, Engel já discutira o quanto a definição de normal e anormal pela psiquiatria refletiu a sua inserção política e social a 
serviço do controle social. Venancio (2004) analisou as concepções de Juliano Moreira sobre doença mental, raça e sexualidade, concluindo que ele não atribuiu nem à raça nem ao gênero os males mentais sofridos por negros e mulheres. Oda (2004) apresenta o antropólogo, médico legal e psiquiatra, Nina Rodrigues e sua reafirmação da mestiçagem como responsável pela predisposição à alienação mental, à sugestionabilidade e ao desequilíbrio mental. Por fim, Oda e Dalgalarrondo (2004) apresentam ideias de Nina Rodrigues (1862-1906) sobre a capacidade dos negros de manifestarem paranoia. Alguns destes artigos merecem observação.

A importância das duas análises históricas feitas por Masiero $(2002 ; 2005)$ para a Psicologia provém do fato de mostrarem com clareza a força com que as teorias eugênicas penetraram o saber psicológico, que, como a psiquiatria, desempenhou funções sociais e políticas, sobretudo com a utilização da psicometria para o exercício cientificamente justificado da seleção/exclusão dos indesejáveis. E permanece forte até hoje nos ramos mais positivistas e organicistas da Psicologia, devido à crença em sua cientificidade.

O autor relembra o papel fundamental da história da Psicologia na formação do profissional:

Para além de sua suposta neutralidade, no passado ou no presente, a ciência pode servir a interesses de classes ou de justificativas para a segregação de minorias, sobretudo no Brasil, onde as teorias racistas foram outrora cultivadas por uma elite intelectual motivada mais ideológica que cientificamente (Masiero, 2005, p. 205).

Isto nos remete à atual escalada da intolerância racial no Brasil, fato que provavelmente terá impacto na demanda por atendimento de pessoas alvo do racismo, o que reforça a necessidade de consideração das relações raciais pela Psicologia clínica.

Venancio (2004) constatou que Juliano Moreira: (a) transmutou em discurso antideterminista as teorias psiquiátricas organicistas alemãs; (b) teria considerado a degeneração como doença mental, porém sem qualquer ligação com raça, cor ou nacionalidade; (c) nos textos pesquisados não se encontrou conexão entre sífilis e raça, tampouco referências conectando a origem da degeneração à natureza feminina. Sendo negro e tendo tido mestres brancos e formação organicista e eurocêntrica, este psiquiatra parece ter vivido à frente do seu tempo (1873-1933). É também digno de nota que tenha sido necessário um psiquiatra negro para discordar da base dita científica da eugenia.

O nono artigo nesta categoria, de Santos et al. (2012), apresenta um histórico do pensamento psicológico brasileiro sobre as relações étnico-raciais. Os autores identificaram uma linha no tempo por onde velejou o pensamento psicológico brasileiro, "momentos de ruptura e de configuração de novos saberes em Psicologia" (p. 174), relativos à compreensão da alteridade, do poder e da intersubjetividade. O primeiro momento, denominado biológico-causal, do final do século XIX ao início do século XX, caracterizou-se pelo estabelecimento do modelo médico psicológico. Nesse período incluem-se os demais oito artigos históricos. Os outros períodos foram denominados culturalista, com a desconstrução do determinismo biológico (de 1930 a 1950) e relacional (a partir de 1990), caracterizado pelo início dos estudos sobre branqueamento e branquitude (Santos et al., 2012).

Nota-se nesta categoria, que os estudos de abordagem histórica tratam, na maioria, de temas psiquiátricos, e visitam o passado sem avançar, no entanto, proposta ou chamamento para o presente ou para o futuro. Dos nove textos desta categoria, apenas dois foram escritos por psiquiatras; no entanto, seis textos - teóricos - versaram sobre a psiquiatria. Esses dados levantam um questionamento sobre a ação da psiquiatria brasileira contemporaneamente, no que diz respeito ao racismo dentro dos serviços de saúde mental. Já os textos de Psicologia nesta categoria, mesmo tendo abordagem histórica trazem, ao contrário, alguma recomendação à guisa de conclusão. Não cremos ser cedo demais para supor que a Psicologia se adiantou à psiquiatria em seu interesse por relações étnico-raciais e saúde mental e pela consequente produção científica a respeito da temática. Na verdade, o artigo de Santos et al. (2012) constata a preocupação com relações raciais na Psicologia desde a década de 1930, tendo sido, porém, restrita à Psicologia social.

\section{Tema C: Percepção de psicólogos da saúde sobre o racismo}

Nesta categoria foi obtido apenas um artigo, Tavares, Oliveira e Lages (2013), cuja primeira autora é profissional de Psicologia, e cujo periódico é da área de saúde. Neste estudo empírico, sete psicólogos do setor de Psicologia de três hospitais públicos de Belo Horizonte passaram por entrevista semiestruturada. 
Os dados foram interpretados por análise de conteúdo. Identificaram-se seis núcleos temáticos: (a) percepção do racismo institucional; (b) iniquidade em saúde; (c) conhecimento sobre as leis e ações afirmativas em prol da promoção da igualdade racial; (d) interpretação dos psicólogos sobre o racismo; (e) existência de preconceitos e discriminação dentro dos centros de saúde; efeitos psicossociais do racismo; (f) papel da Psicologia frente ao racismo institucional na saúde.

Apenas uma profissional percebeu a existência do tratamento desigual no atendimento a usuários negros. As relações étnico-raciais, notadamente o racismo, não são problematizadas pelos profissionais, ou seja, as desigualdades são naturalizadas, não questionadas, invisíveis. Um profissional deixou transparecer uma sugestão de branqueamento como saída, que é a ideologia da miscigenação como solução para a opressão do negro. Nenhum profissional soube definir racismo institucional. Os profissionais desconheciam as vulnerabilidades específicas da população negra. Apenas dois entrevistados assinalaram conhecer anemia falciforme, e nenhum soube nomear qualquer outra patologia, sequer as psicológicas, originadas por preconceito e discriminação. Todos os profissionais desconhecem as Políticas Municipais tanto de Saúde da População Negra, de 2008, quanto de Promoção da Igualdade Racial, de 2010.

Não apareceu nas entrevistas o adoecimento psíquico como resultante das relações étnico-raciais malfazejas. Tampouco o silêncio e a inexistência de denúncia por mau tratamento devido à cor foram vistos pelos profissionais como sinais do preconceito e discriminação. As autoras concluem pela ausência de percepção do racismo institucional por parte dos profissionais entrevistados e sugerem como solução os cursos de formação em Psicologia e a implementação, pelos Conselhos, de ações para sensibilizar e instrumentar a categoria.

Este artigo é particularmente significativo por retratar o desconhecimento praticamente total, por parte dos psicólogos, da realidade da população negra a quem atende rotineiramente, uma vez que trabalham em hospital público. $\mathrm{O}$ desconhecimento das políticas públicas já existentes em benefício da população negra nos leva à conclusão de que esses profissionais lidam com essa população com base em padrões díspares da realidade negra. O estudo evidencia, sobretudo, a lacuna na formação do psicólogo no que tange as relações étnico-raciais, principalmente as especificidades da saúde da população negra e o racismo institucional, sobremaneira invisibilizado.

\section{Tema D: A Psicologia clínica/ psiquiatria nas relações raciais ou nas relações que envolvam alteridade}

Nesta categoria foram incluídos cinco artigos, sendo um relativo a intervenção (Guimarães, \& Podkameni, 2008), dois tratam de análise social da temática (Pavão, Ploubidis, Werneck, \& Campos, 2012; Zamora, 2012) e outros dois dizem respeito à formação do psicólogo e seu comprometimento social (Azeredo, 2002; Delfino, Reis Filho, Foscarini \& Avelino, 2001). Quanto à área de atuação dos profissionais, quatro eram da Psicologia (Azeredo, 2002; Delfino et al., 2001; Guimarães, \& Podkameni, 2008; Zamora, 2012) e um da área de Medicina Social (Pavão et al., 2012); por periódico de publicação, um é da área de Saúde Social (Guimarães, \& Podkameni, 2008), dois de Psicologia (Azeredo, 2002; Zamora, 2012), um de Psicanálise (Delfino et al., 2001) e um de Etnia e Doença (Pavão et al., 2012).

Guimarães e Podkameni (2008) realizaram estudo empírico de 1999 a 2000, junto a gestantes negras e não negras no Rio de Janeiro, tendo por método a pesquisa-ação e a observação participante, baseados no pensamento teórico clínico winnicottiano, e tendo como estratégia de intervenção a Rede de Sustentação Coletiva. O conceito de "situação conflitual traumatizante" foi desenvolvido pelos autores e diz respeito ao prejuízo na manutenção e realimentação do espaço potencial winnicottiano, que, no caso da população negra, é gerado pela vivência contínua em um ambiente nocivo. O racismo fomenta situações conflituais traumatizantes. A Rede de Sustentação coletiva é a intervenção criada pelo primeiro autor, para atender a situação traumatizante por meio da manutenção e realimentação do campo subjetivo. Os autores avaliaram positivamente o projeto como facilitador da elaboração e do escoamento psíquicos. Concluíram que a experiência da Rede de Sustentação Coletiva pode ser utilizada como estratégia possível para obstrução dos efeitos nocivos do meio ambiente sociocultural brasileiro sobre a saúde mental afrodescendente.

Nos dois artigos relativos à análise social da temática, primeiramente, Pavão et al. (2012) verificaram o impacto da discriminação racial na saúde da população negra no Brasil, investigando a associação entre discriminação racial e três efeitos na saúde: autopercepção da saúde (SRH), morbidade física e depressão. 
Como resultados: (a) a discriminação racial teve uma forte associação com três aspectos pesquisados: autoavaliação da saúde, morbidade física e depressão; (b) a experiência de qualquer nível de discriminação racial foi associada a um aumento de 1,4 vezes na probabilidade de se ter uma saúde fragilizada; (c) a depressão foi o efeito na saúde que apresentou a associação mais pronunciada com a discriminação racial.

No segundo artigo, Zamora (2012) utiliza o modelo da produção de subjetividade e da concepção de biopoder de Foucault para examinar estudos que tratam das consequências do racismo como veículo de subjetivação. A autora apresenta noções de raça, racialismo e racismo e dados concretos sobre a desigualdade racial no Brasil e demonstra como a desigualdade não pode ser reduzida somente à pobreza. Zamora aponta a incongruência do racismo brasileiro sem racistas: enxerga-se o preconceito racial na sociedade brasileira, sem que, no entanto, a pessoa se veja como preconceituosa. São apontadas outras especificidades do racismo brasileiro: fortes resistências à mudança baseadas no persistente mito da democracia racial; desqualificação das tentativas de solução das iniquidades sociais como racismo inverso; atribuições à raça de traços negativos dos negros. A autora menciona Bento (2003), que revela a negação do racismo implícito nessas e outras práticas de violência brutal, bem como a dificuldade de destacar-se como negro, por ser sempre "o estranho no ninho" sem poder contrapor-se a uma opressão que não é assumida. A autora identifica como o local desprivilegiado de subjetivação do negro afeta sua saúde física e mental, além de reduzir-lhe várias oportunidades em termos de garantia de direitos e cidadania. Zamora conclui apontando a urgência da necessidade de políticas públicas com a participação da população negra, e identifica também a necessidade de aumentar a ainda incipiente produção da Psicologia clínica brasileira no campo das relações étnico-raciais, e de se repensar a formação do psicólogo clínico e seu papel social (Zamora, 2012).

Para responder à pergunta "o que escuta um psicanalista quando fala um negro?", Delfino et al. (2001) fizeram uma reflexão a respeito dos efeitos, sobre o psiquismo dos negros, da associação histórica do fracasso ao negro. Os autores se perguntam de que um psicanalista não dá conta, quando ele interpela o psicanalista negro para encaminhar-lhe um cliente negro sob a alegação de que "Não dou conta de trabalhar com negro".
É descrito muito apropriadamente o desenvolvimento da relação do negro com seu corpo, objeto a ser lapidado pelo olhar alheio, de um padrão que sequer se assemelha ao seu próprio. O que o negro busca é, segundo os autores, simplesmente "ser negro" (Delfino et al., 2001). Os autores questionaram, ainda, se estariam os psicanalistas, inclusive psicanalistas negros, preparados para o processo analítico de pessoas negras. Por fim, advertiram que o não receber clientes negros equivaleria a falhar, pois o cliente negro deveria representar um convite a novas leituras que alcancem além do corpo negro no divã, e conclamaram a essa releitura. Afinal, o inconsciente que está sendo ouvido, "não tem cor, nem sexo, nem idade" (Delfino et al.2001). Consideramos que uma releitura de teorias euro-centradas sob o viés das relações étnico-raciais, bem como a apropriação de teorias afrocentradas, são primordiais na formação de todos os profissionais da saúde mental.

Azerêdo (2002) também defende a necessidade de suprir a falha de formação em Psicologia no que tange à dimensão política como abertura para todas as diversidades. As explicações não consideram aspectos sociais produtores de grandes problemas mentais e sociais, em uma sociedade onde a pluralidade impera, mas é esquecida como motivadora da separação da sociedade em coletividades raciais, étnicas, de gênero, de classe, conforme a conveniência do poder estabelecido. Ao terminar sua formação, o psicólogo está familiarizado com o enfoque individualista e alheio a questões sociais; as questões raciais, étnicas, de gênero e de classe tendem a permanecer invisíveis, uma vez que o profissional não foi exposto à busca de soluções coletivas para resolver a questão da desigualdade. A autora finaliza apresentando sua experiência docente inspirada na técnica do grupo operativo, de Enrique Pichón-Rivière, "para criar uma metodologia de ensino que possibilite a expressão da diversidade e o restabelecimento da pluralidade" (p. 19), e lidar com a questão da construção da identidade de grupos excluídos (mulheres, imigrantes nordestinos, travestis e negros).

\section{Tema E: Crítica epistemológica/ metodológica à Psicologia}

Esta categoria inclui dois artigos: Santos e Martins (2013) e Oliveira (2002), cujos autores são profissionais da área de Psicologia e o periódico de publicação é também da Psicologia. Santos e Martins (2013) 
criticaram as metodologias científico-naturais, que dissociam os fenômenos de seus contextos sociais, humanos e ecológicos e desconsideram as categorias intencionais e valorativas, impedindo a compreensão das atividades humanas que incluem valores, principalmente os éticos e políticos. Apresentaram a Psicologia crítica como uma alternativa para dar conta dos pontos cegos do cientificismo na atividade teórica e prática da Psicologia, com a função de "desconstruir, reconstruir e construir o conhecimento psicológico" (p. 50) visando à mudança de suas práticas. Oliveira (2002) fez uma análise histórico-filosófica do preconceito, mostrando suas raízes sociais, como uma construção a serviço da ideologia dominante de base europeia, em cujos mitos estamos mergulhados. A base da discriminação é a presença de qualquer característica indesejada pelo grupo dominante e não segue qualquer raciocínio lógico e/ou prova científica. O desafio da Psicologia estaria então em desvencilhar-se da ideologia dominante e abrir-se para a pluralidade e produzir conhecimento científico sério como forma de afastamento do mito.

A crítica ao eurocentrismo apontou que a ordem tida como universal não consegue dar conta da pluralidade das experiências humanas (Nascimento, 2009). Paradigmas não eurocêntricos são: (a) a psicoterapia multicultural, que reconhece o impacto de fatores raciais, étnicos e culturais na psicoterapia e, por isso, leva em conta a experiência de vida e valores culturais do(a) cliente na definição dos objetivos da psicoterapia e tenta balancear estratégias universais com estratégias específicas da cultura (Sue, \& Sue, 2003); e (b) o paradigma afrocêntrico, que não se concilia com hegemonia nem com idealismo, baseia-se na ideia de que a sanidade dos povos africanos será alcançada via reafirmação do sentido de agência, tendo o povo negro como protagonista e sujeito do conhecimento (Nobles, 2009).

\section{Considerações finais}

O objetivo do presente estudo foi realizar um levantamento da produção científica a respeito dos impactos do racismo na saúde mental da população negra e, ao mesmo tempo, verificar a contribuição da Psicologia nessa produção. O resultado alcançado na presente revisão de literatura revelou-se insatisfatório. A discussão da temática no Brasil mostrou-se muito incipiente, ainda que a Psicologia tenha promissoramente contribuído mais que a psiquiatria em termos de proposições.
No que se refere a limitações deste estudo aponta-se o critério que exclui a produção acadêmica não publicada em periódico indexado a uma das plataformas pesquisadas. Artigos não indexados não aparecem nesta pesquisa, o que não quer dizer que não existam. Foram localizados artigos a partir das referências dos artigos alvo deste trabalho, que, embora de qualidade razoável, não constaram do levantamento bibliográfico por não estarem indexados.

A partir da leitura dos dezenove artigos pode-se depreender o seguinte:

1. É incipiente a pesquisa em relações étnico-raciais e saúde mental no Brasil.

2. É importante a pesquisa da interseccionalidade no caso das mulheres negras.

3. As teorias raciais, a eugenia e o racismo científico ainda têm forte rastro sobre a Psicologia e a psiquiatria brasileiras, refletidas no desempenho de funções sociais e políticas.

4. Os psicólogos da saúde parecem ter pouca percepção das relações étnico-raciais deletérias no Brasil, e não será fora de mira afirmar o mesmo dos psicólogos de outras áreas, principalmente a clínica.

5. A depressão é um dos efeitos mais pronunciados das experiências de discriminação racial sobre a saúde mental da população negra.

6. Quando adequadamente contemplados os efeitos nocivos do racismo brasileiro na saúde psíquica dos afrodescendentes podem ser obstruídos.

7. É necessário um esforço de releitura, sob um olhar crítico negro, das teorias euro-centradas, quando não a adoção de teorias afro-centradas.

8. A Psicologia ignora aspectos políticos e sociais geradores de problemas mentais e sociais; é necessário que a Psicologia: (a) passe a considerar mais o coletivo; (b) enfrente o desafio de desapegar-se da ideologia dominante e abra-se para outras formas epistemológicas; e, (c) utilize-se da Psicologia crítica para instrumentar a mudança em suas práticas metodológicas.

O cenário das pesquisas apresentadas aponta, portanto, a necessidade urgente de ênfase investigativa, na agenda da Psicologia clínica, dos impactos do racismo na saúde mental de pessoas negras, vistos de uma perspectiva dual, qual seja, tanto a vivência diária do racismo como estressor e causador de sofrimento, quanto o racismo invisível dos serviços de saúde mental, que primariamente deveriam acolher a pessoa alvo do racismo. É também mister a des- 
construção da psiquiatrização racial e consequente medicalização do negro - resquício das práticas psiquiátricas do Brasil do início do século XX, de inspiração racista eugênica (Costa, 2007; Zanello, \& Gouveia, 2016) - por meio de uma nova organização do serviço de saúde mental como um todo. Para tanto, precisamos de reflexão acadêmica equilibrada com a reflexão política. As pesquisas da área clínica podem dialogar fartamente com a Psicologia social, utilizando seu arcabouço teórico, por ser a subárea da Psicologia de maior produção de conhecimento sobre o tema, como verificaram Martins, Santos e Colosso (2013). Lamentavelmente, relações étnico-raciais na saúde mental continuam não sendo tema para a pesquisa psicológica clínica.

Vale apontar aqui a existência de uma lacuna estatística nos serviços de saúde no Brasil com relação ao pertencimento étnico-racial da população atendida. Persiste a dificuldade prática de implementação do quesito cor ou raça/etnia nos cadastros de tais serviços, mesmo tendo o Brasil assumido o compromisso na Conferência Mundial de Durban, em 2001, de cumprir políticas e práticas de coleta e desagregação de dados, pesquisas e estudos nessa área. A população negra passou de minoria a maioria, mas permanece invisível. A parcela da população negra brasileira atendida em serviços de saúde mental como um todo (aconselhamento, assistência social, psicoterapia e psiquiatria), consequentemente permanece invisível, uma vez que a coleta de dados relativos ao pertencimento étnico-racial não é feita. As palavras de Jewel (2002) ainda se aplicariam aqui e agora: clientes de minorias raciais e étnicas continuam a ser desconhecidos. E são consequentemente mal servidos.

É igualmente necessário promover maior consciência e compreensão de como o racismo opera, a mul- tiplicidade de suas manifestações e o impacto que tem sobre as pessoas. É importante estudar e reconhecer este impacto para que as consequências das agressões raciais não continuem sendo ignoradas, subestimadas, invisibilizadas. É imprescindível a realização de pesquisas para se traduzirem em práticas as recomendações da Resolução no 018/02, que "Estabelece normas de atuação para os psicólogos em relação ao preconceito e à discriminação racial" (CFP, 2002). No nível governamental, a preocupação do Ministério da Saúde com o racismo como causador de sofrimento psíquico e da relação inversa entre racismo e saúde mental, geralmente ignorada nos serviços de saúde mental, resultou na criação do Grupo de Trabalho Racismo e Saúde Mental (Brasil, 2016). Apesar de seu importante trabalho de conscientização, o Grupo sofre, no momento, interrupção de atividades, em função das mudanças políticas de nossa história recente.

O racismo no Brasil é um fenômeno ao mesmo tempo presente e negado (Zamora, 2012). Os profissionais da saúde mental são incapazes de reconhecer a linguagem, o comportamento e as atitudes racistas internalizadas de seu próprio racismo encoberto. Para o usuário afrodescendente, tal experiência estressante e traumática tem efeito cumulativo ao longo da vida e impactará a saúde mental da pessoa. O profissional que, teoricamente, contribuiria para o alívio da pessoa, ao contrário, lhe inflige mais dor. Essa invisibilidade do racismo no campo dos dispositivos da saúde mental é aparentemente ainda muito pouco problematizada. Assim, a inserção da temática do racismo como estressor responsável por dor, sofrimento e até morte, na agenda da Psicologia deve ser feita não apenas de forma transversal no currículo, mas também como disciplina específica; é necessária no ensino/treinamento, na prática clínica, e na pesquisa psicológica.

\section{Referências}

Azerêdo, S. M. (2002). O político, o público e a alteridade como desafios para a psicologia. Psicologia: Ciência e Profissão, 22(4), 14-23. https://doi.org/10.1590/S1414-98932002000400003

Bardin, L. (2011). Análise de conteúdo. São Paulo: Edições 70.

Bastos, J. L., Barros, A. J., Celeste, R. K., Paradies, Y., \& Faerstein, E. (2014). Discriminação de idade, classe e raça: suas interações e associações com saúde mental em estudantes universitários brasileiros. Cadernos de Saúde Pública, 30(1), 175-186. https://doi.org/10.1590/0102-311X00163812

Bento, M. A. (2003). Branqueamento e branquitude no Brasil. In: I. Carone, \& M. A. Bento (Eds.), Psicologia social do racismo: Estudos sobre branquitude e branqueamento no Brasil (2 ed., pp. 25-57). Petrópolis, RJ: Vozes.

Brasil. (2013). Ministério da Saúde, Secretaria de Gestão Estratégica e Participativa. Política nacional de saúde integral da população negra: uma política do SUS. Brasília, DF: Ministério da Saúde. 
Psicologia: Ciência e Profissão Jul/Set. 2018 v. 38 n³, 450-464.

Brasil. (2016). Ministério da Saúde, Secretaria de Gestão Estratégica e Participativa. Temático Saúde da População Negra. Brasília, DF: Ministério da Saúde.

Carter, R. T. (2007). Racism and psychological and emotional injury: Recognizing and assessing race-based traumatic stress. Counseling Psychology, 35(1), 13-105. https://doi.org/10.1177/0011000006292033

Carter, R. T., Nazzula, S., Victoria, R., Vasquez, R., Hall, S., Smithe, S. et al. (2013). Initial development of the race-based traumatic stress symptom scale: assessing the emotional impact of racism. Psychological Trauma: Theory, Research, Practice, and Policy, 5(1), 1-9. https://doi.org/10.1037/a0025911

Conselho Federal de Psicologia - CFP. (2002). Resolução CFP No 018/2002. Estabelece normas de atuação para os psicólogos em relação ao preconceito e à discriminação racial. Brasília, DF: Conselho Federal de Psicologia.

Costa, J. F. (2007). História da Psiquiatria no Brasil: Um corte ideológico (5a ed. rev.). Rio de Janeiro, RJ: Garamond.

Cruz, I. F. (2004). A sexualidade, a saúde reprodutiva e a violência contra a mulher negra: Aspectos de interesse para assistência de enfermagem. Revista da Escola de Enfermagem da USP, 38(4), 448-457. https://doi.org/10.1590/ S0080-62342004000400011

Delfino, E. M., Reis Filho, J. T., Foscarini, S. R., \& Avelino, W. (2001). Violência e questão racial no Brasil: uma leitura psicanalítica. Reverso, 23(48), 17-23.

Engel, M. G. (1999). As fronteiras da anormalidade: psiquiatria e controle social. História, Ciências, Saúde-Manguinhos, 5(3), 547-563. https://doi.org/10.1590/S0104-59701999000100001

Fanon, F. (2008). Pele negra, máscaras brancas. Salvador, BA: EDUFBA. (Originalmente publicado em 1952).

Guimarães, M. A., \& Podkameni, A. B. (2008). A rede de sustentação coletiva, espaço potencial e resgate identitário: projeto mãe-criadeira. Saúde e Sociedade, 17(1), 117-130. https://di.org/10.1590/S0104-12902008000100011

Helms, J. E. (1984). Toward a theoretical explanation of the effects of race on counselling: A black and white model. Counseling Psychology, 12, 153-165.

Helms, J. E., \& Cook, D. A. (1999). Using race in counseling and psychotherapy: Theory and process. Needham, MA: Allyn \& Bacon.

Heringer, R. (2002). Desigualdades raciais no Brasil: Síntese de indicadores e desafios no campo das políticas públicas. Cadernos de Saúde Pública, 18(Suppl.), 57-65. https://doi.org/10.1590/S0102-311X2002000700007

Instituto Brasileiro de Geografia e Estatística - IBGE. (2015). Pesquisa nacional por amostra de domicílios: síntese de indicadores 2013 (PNAD 2013) (2a ed.). Rio de Janeiro, RJ: o autor.

Igreja, R. L. (2016). Combate al racismo y la discriminación racial en Brasil: Legislación y acción institucional. Desacatos, 51, 32-49.

Jewel, P. (2002). Multicultural counselling research: An evaluation with proposals for future research. In: S. Palmer (Ed.), Multicultural counseling: A reader (pp. 241-267). London: Sage.

Kerner, I. (2012). Tudo é interseccional? Sobre a relação entre racismo e sexismo. Novos Estudos CEBRAP, 93, 45-58. https://doi.org/0.1590/S0101-33002012000200005

Koller, S. H., Couto, M. C., \& Hohendorff, J. V. (2014). Manual de produção científica. Porto Alegre, RS: Penso.

Lins, S. L., Lima-Nunes, A., \& Camino, L. (2014). O papel dos valores sociais e variáveis psicossociais no preconceito racial brasileiro. Psicologia e Sociedade, 26(1), 95-105.

Maio, M. C. (2001). UNESCO and the study of race relations in Brazil: Regional or national issue? Latin American Research Review, 36(2), 118-136.

Martins, E., Santos, A. D., \& Colosso, M. (2013). Relações étnico-raciais e psicologia: publicações em periódicos da SciELO e Lilacs. Psicologia: Teoria e Prática, 3, 118-133.

Masiero, A. L. (2002). "Psicologia das raças" e religiosidade no Brasil: Uma intersecção histórica. Psicologia: Ciência e Profissão, 22(1), 66-79. https://doi.org/10.1590/S1414-98932002000100008

Masiero, A. L. (2005). A Psicologia racial no Brasil (1918-1929). Estudos de Psicologia, 10(2), 199-206. https://doi. org/10.1590/S1413-294X2005000200006 
Munanga, K. (2003). Prefácio. In: I. Carone, \& M. A. Bento (Eds.), Psicologia social do racismo (2a ed., pp. 9-11). Petrópolis, RJ: Vozes.

Nascimento, E. L. (2009). O olhar afrocentrado: Introdução a uma abordagem polêmica. In: E. L. Nascimento, Afrocentricidade: Uma abordagem epistemológica inovadora (pp. 181-196). São Paulo, SP: Selo Negro.

Nobles, W. (2009). Sakhu Sheti: Retomando e reapropriando um foco psicológico afrocentrado. In: E. L. Nascimento (Ed.), Afrocentricidade: Uma abordagem epistemológica inovadora (pp. 277-297). São Paulo, SP: Selo Negro.

Nunes, S. S. (2006). Racismo no Brasil: tentativas de disfarce de uma violência explícita. Psicologia USP, 17(1), 89-98.

Oda, A. M. (2004). Nina Rodrigues e A loucura epidêmica de Canudos. Revista Latinoamericana de Psicopatologia Fundamental, 3(2), 139-144. https://doi.org/10.1590/1415-47142000002009

Oda, A. M., \& Dalgalarrondo, P. (2004). Uma preciosidade da psicopatologia brasileira: A paranoia nos negros, de Raimundo Nina-Rodrigues. Revista Latinoamericana de Psicopatologia Fundamental, 7(2), 147-160. https://doi. org/10.1590/1415-47142004002010

Oliveira, C. M. (2002). Pluralidade racial: um novo desafio para a psicologia. Psicologia: Ciência e Profissão, 22(4), 34-35. https:// doi.org/10.1590/S1414-98932002000400005

Organização Mundial da Saúde - OMS. (2001). Relatório sobre a saúde no mundo 2001: Saúde mental: Nova concepção, nova esperança. Genebra: o autor.

Paradies, Y. (2006). A systematic review of empirical research on self-reported racism and health. International Journal of Epidemiology, 35, 888-901. https://doi.org/10.1093/ije/dyl056

Pavão, A. L., Ploubidis, G. B., Werneck, G., \& Campos, M. R. (2012). Racial discrimination and health in Brazil: Evidence from a population-based survey. Ethnicity and Disease, 22(3), 353-359.

Pieterse, A. L., Todd, N. R., Neville, H. A., \& Carter, R. T. (2012). Perceived racism and mental health among black american adults: A meta-analytic review. Counseling Psychology, 59(1), pp. 1-9. https://doi.org/10.1037/a0026208

Ridley, C. R. (2005). Overcoming unintentional racism in counseling and therapy: A practitioner's guide do intentional intervention. London: Sage.

Santos, A. O., \& Schucman, L. V. (2015). Desigualdade, relações raciais e a formação de psicólogo(as). Revista EPOS, 6(2), 117-140.

Santos,A.O.,Schucman,L.V.,\&Martins,H.V.(2012).Brevehistóricodopensamentopsicológicobrasileirosobrerelações étnico-raciais. Psicologia:CiênciaeProfissão,32(esp.),166-175.https://doi.org/10.1590/S1414-98932012000500012

Santos, H. P., \& Martins, J. B. (2013). O cientificismo como obstáculo à compreensão ético-política da psicologia. Psicologia: Ciência e Profissão, 33(esp), 42-53.

Schucman, L. V. (2014). Sim, nós somos racistas: Estudo psicossocial da branquitude paulistana. Psicologia \& Sociedade, 26(1), 83-94. https://doi.org/ 10.1590/S0102-71822014000100010

Serra, L. N., \& Scarcelli, I. R. (2014). Por um sangue bandeirante: Pacheco e Silva, um entusiasta da teoria eugenista em São Paulo. Revista Latinoamericana de Psicopatologia Fundamental, 17(1), 85-99. https://doi.org/10.1590/ S1415-47142014000100007

Silva, M. L. (2005). Racismo e os efeitos na saúde mental. In: L. E. Batista, S. Kalckmann (Orgs.), Seminário saúde da população negra do Estado de São Paulo 2004 (pp. 129-132). São Paulo, SP: Instituto de Saúde.

Silvério, V. R., \& Trinidad, C. T. (2012). Há algo novo a se dizer sobre as relações raciais no Brasil contemporâneo? Educação \& Sociedade, 33(120), 891-914. https://doi.org/10.1590/S0101-73302012000300013

Sue, D. W., \& Sue, D. (2003). Counseling the culturally diverse: Theory and practice. New York: John Wiley \& Sons.

Sue, D.W., \& Sue, D. (2016). Counseling the culturally diverse: theory and practice (Kindle Ed.). Hoboken, New Jersey: John Wiley \& Sons.

Tavares, N. O., Oliveira, L. V., \& Lages, S. R. (2013). A percepção dos psicólogos sobre o racismo institucional na saúde pública. Saúde em Debate, 37(99), 580-587. https://doi.org/10.1590/S0103-11042013000400005

Venancio, A. T. (2004). Doença mental, raça e sexualidade nas teorias psiquiátricas de Juliano Moreira. PHYSIS: Revista Ciência \& Saúde Coletiva, 14(2), pp. 283-305. https://doi.org/10.1590/S0103-73312004000200006 
Weyler, A. R. (2006). A loucura e a república no Brasil: A influência das teorias raciais. Psicologia USP, 17(1). https:// doi.org/10.1590/S0103-65642006000100003

Zamora, M. H. (2012). Desigualdade racial, racismo e seus efeitos. Fractal, 24(3), 563-578. https://doi.org/10.1590/ S1984-02922012000300009

Zanello, V., \& Gouveia, M. (2016). Psiquiatria e racismo. In: F. C. Lemos, D. Galindo, P. P. G. Bicalho, E. T. A Ferreira, B. A. Cruz, T. S. Nogueira et al. (Orgs.), Práticas de judicialização e medicalização dos corpos no contemporâneo (Vol. 5, pp. 73-80). Curitiba, PR: CRV.

\section{Marizete Gouveia Damasceno}

Doutoranda em Psicologia Clínica e Cultura, Departamento de Psicologia Clínica, Instituto de Psicologia, Universidade de Brasília E-mail: mariz.terra@gmail.com

Valeska M. Loyola Zanello

Profa. Dra. Departamento de Psicologia Clínica, Instituto de Psicologia, Universidade de Brasília valeskazanello@gmail.com

Endereço para envio de correspondência:

Universidade de Brasília. Instituto de Psicologia. Departamento de Psicologia Clínica

Asa Norte. CEP: 70910-900.

Brasília - DF. Brasil.

Recebido 08/08/2017

Reformulado 07/05/2018

Aprovado 04/06/2018

Received 08/08/2017

Reformulated $05 / 07 / 2018$

Approved 06/04/2018

Recibido 08/08/2017

Reformulado 07/05/2018

Aceptado 04/06/2018

Como citar: Gouveia, M. \& Zanello, V. (2018). Saúde mental e racismo contra negros: Produção bibliográfica brasileira dos últimos quinze anos. Psicologia: Ciência e Profissão, 38(3), 450-464. https://doi.org/10.1590/1982-37030003262017

How to cite: Gouveia, M. \& Zanello, V. (2018). Mental health and racism against blacks:

Brazilian publications within the last fifteen years. Psicologia: Ciência e Profissão, 38(3), 450-464. https://doi.org/10.1590/1982-37030003262017

Cómo citar: Gouveia, M. \& Zanello, V. (2018). Salud mental y racismo contra negros: Producción bibliográfica brasileña de los últimos quince años. Psicologia: Ciência e Profissão, 38(3), 450-464. https://doi.org/10.1590/1982-37030003262017 